\title{
The Influences of Pair Discussion on Nursing Students' Learning Experience in Problem-Based Learning: A Qualitative Inquiry
}

\author{
Oonhee Yee ${ }^{1}$, Juyoung $\mathrm{Ha}^{2}$, and Youngmi $\mathrm{Ahn}^{3}$ \\ ${ }^{1}$ Dept. of Nursing, Baekseok Culture University, Korea \\ ${ }^{2}$ College of Nursing, Pusan National University, Korea \\ ${ }^{3}$ Dept. of Nursing Science, Baekseok University, Korea \\ 1ohyee@bscu.ac.kr, ${ }^{2}$ jyha10289@pusan.ac.kr, ${ }^{3} y a h n @ b u . a c . k r$
}

\begin{abstract}
The purpose of this study was to analyze the influences of pair discussion on learning experiences of nursing students in PBL class. As a result of the qualitative content analysis of the related statements extracted from the learner's reflection journal written by nursing students, it was found that the pair discussion experienced by the participants in the PBL process affected the three areas of their learning experiences including learning ability, problem solving ability and communication ability. The findings of this study are expected to provide basic data useful for the development and application of instructional design and teaching methods.
\end{abstract}

Keywords: Nursing, Student, Learning experience, Problem-based learning, Pair discussion, Qualitative inquiry

\section{Introduction}

In recent years, nurses' problem solving abilities have become more important, and nursing education is also operating curriculum to achieve these core competencies [1][2][3]. This is because it is required to acquire necessary information based on critical thinking and logical thinking in the face of unpredictable situations and to have the ability to solve problems effectively through accurate situation judgment [2].

Although traditional teaching-oriented lecture-based education methods provide students with a lot of information in a short period of time, it has been pointed out that there is a limit to the education methods as it does not help students to remember the information from their learning [4]. Problem-based learning (PBL) has been proposed to overcome these limitations. PBL has been evaluated as an educational method to improve problem solving ability and critical thinking tendency of nursing students as well [5][6]. In addition, PBL has been reported as it improved learning ability of nursing students by improving their meta-cognition, that is self-awareness of the process of thinking and ability of adjusting the process and using his/her gained knowledge [3], and by improving their self-directed learning ability [6].

Students in PBL are sub-grouped to receive clinical patient questions and participate in discussions to find and solve the cause of the clinical problem. Through the discussion process, students can improve basic medical knowledge, nursing knowledge, integration of

Article history:

Received (February 4, 2018), Review Result (March 16, 2018), Accepted (April 20, 2018) 
clinical knowledge, hypothesis deduction ability, self-directed learning ability, cooperative learning ability and communication ability. However, it has been reported that not all the students participating in the learning process actively participate in learning activities as required by the PBL [7][8]. Therefore, in order to expect the effectiveness of the PBL learning method, students should be provided with the opportunity to acquire and train learning methods such as discussion skills, critical thinking skills and arguing skills, and to find ways to reduce the burden on learning activities.

Pair discussion is a discussion method used in Havruta known as Jewish education [9]. Although Havruta is similar to the existing discussion class, there is a difference between those two discussion methods. The goal of general classroom discussion is usually determined at the beginning of the discussion while the goal of Havruta education is to develop the thinking power of learners and to promote them to find various answers in the process of discussion [10].

Havruta is basically a process of communication that involves a process in which two or three people pair up, ask questions to each other, answer the other's questions and explain their opinions. It has been reported that the education method of Havruta was effective in raising communication ability, listening ability, and persuasion ability, and has a positive effect on interpersonal relations and creativity of individuals and groups as well as critical thinking and problem solving ability [11][12].

The purpose of this study was to investigate the influences of pair discussion on learning experiences of nursing students in the PBL class and to discuss educational strategies for effective PBL class in nursing education. In this paper, we want to report the results of the ongoing research.

\section{Research methods}

This is a qualitative inquiry using content analysis to investigate the influences of pair discussion on learning experiences of nursing students in PBL class based on the reflection journal prepared by the students.

The course selected for this study consisted of applying a pair discussion as a part of the entire PBL class operated as a regular curriculum at a university in Korea and asking students to write a reflective journal about their learning. The course was designed to allow students to meet a patient with certain health problems in a scenario though the PBL process, to find problem solving methods throng group activities, and to practice the patient's nursing problem solving process through simulation. The course obtained 5 domains of learning including PBL class as a part of learning so all of the participants were assigned to participate in 5 PBL class until the end of the course.

All participants had already participated in two or three PBL lessons in the subject before participating in the study, and it was the first experience of participating in pair discussion for all of the participants. In the class with additional pair discussion, all participants went through 'learning plan - pair discussion - group discussion - whole discussion - reflection'. In the data collection, students were asked to submit the "Learner Reflection Journal" written on the day after the class by e-mail to the professor who was in charge of the PBL class.

The collected data were analyzed using qualitative content analysis, which analyze the data and find the meaning of the data [13]. Among 138 students who participated in the class and submitted the learner reflection journal, the relevant contents about 'how a pair discussion influenced the personal learning and problem solving process of nursing students' were extracted and analyzed. 


\section{Results}

The total number of statements related to the pair discussion experience among the 138 nursing students was 248. These statements were analyzed and a total of 245 codes, 29 subcategories, and 3 categories were derived from them (the numbers in parentheses are the number of codes reinterpreted by interpreting participant statements).

\subsection{Influences on learning ability}

In the pair discussion process, the participants experienced 'active learning with his/her leaning partner (34)'. They taught each other, learned each other, and tried to make responsible learning in order to explain well to their partner.

However, a lot of them experienced 'passive learning depending on his/her learning (41)'. The learned from my partner about the contents that they did not prepare though self-directed study, and had the opportunity to supplement what they did not learn yet.

The pair discussion was also an opportunity for some learners to reflect on 'self-reflection of learning (6)'. It was an opportunity to be aware of what their learning methods were like or what the ultimate reason they learned as a nursing student.

Participants in the process of preparing for a pair discussion made an 'effort to acquire accurate knowledge (8)'. These include experience in finding answers to paired questions, whether the knowledge learned is appropriate, and whether there are errors in gained knowledge.

Participants in the process of pair discussion 'learned that there are various ways to use learning materials (5)'. In order to solve the common problem presented, the participants searched for the information respectively but some participants found that both partners brought almost same information. On the other hand, some participants experienced that even though the contents of the subject and the information are same their thoughts about the priority and the weight were different.

Pair discussion provided opportunities for participants to demonstrate their own learning skills that they had not experienced through individual learning before. In that process, participants 'confirmed that they could get better learning outcomes (30)'.

From the experiences of pair discussion participants had 'a positive conviction about his/her learning ability (34)'. Pair discussion eventually boosted their confidence in depth of learning, extensive learning, use of knowledge, critical thinking for information uses, and thought for learning. They were also committed to the belief that they have learned effective learning methods and to use them in other learning situations in the future.

On one hand, some participants who felt that he or she just began to get used to the PBL method had 'a sense of burden about the new learning method (5)'. On the other hand, the existence of a colleague who had to solve the same task as 'pair' had become a driving force for the PBL to 'reduce the burden on his / her learning under the charge (1)'. Some participants experienced 'enjoyment in learning (6)' that they have not tasted before.

\subsection{Influences on problem solving ability}

As the focus of the PBL was focused on solving the problem, the participants stated that the pair discussion helped solve the problem. One participant experienced 'improvement of learning responsibility (1)'. She felt that the problem-solving process by herself had to do well in order for the problem-solving process with her learning pair to be successful. 
Some participants also experienced a 'rise in confidence (3)' about problem solving as they realized that they had the knowledge needed to solve the problem and that the problem was solved quickly by pairing and teamwork.

In the process of talking about the problem with the partner, some participants felt 'better concentration (5)' than when they solved the problem by themselves.

Many participants experienced the 'expansion of thinking (23)' necessary for problem solving by learning various perspectives of problem recognition and approach in problem solving process with their learning partner.

As the debate progressed, they became more confident in approaching and solving the giving problems. This was based on learning what kind of thinking process was needed to approach the problem and 'improving their critical thinking ability (2)'.

Participants had more discussion opportunities in pair discussion than group discussions in other PBL so that they experienced a change of awareness for problem solving such as 'awareness of the importance of cooperation (4)' and 'learning the attitude how to cooperate with other health professions (1)'.

Participants felt pressor from the PBL class because they should complete solving problems within the given time. Pair discussions have 'reduced such burdens (1)' and even 'increased relief (1)' for problem solving, because the presence of a partner was the object of companion for cooperation and consultation.

It was much easier to approach and to solve their given problems in PBL with previous pair discussion then in PBL with ordinary discussion. This was because they thought that they already 'secured the comrades to solve the problem with (8)', and 'secured useful knowledge and information (8)' necessary for the problem solving with the comrades.

\subsection{Influences on communication ability}

There were several statements describing the positive (mostly) influences on communication abilities among participants.

Participants were able to recognize that they were the main character of the discussion because one of the two people participating in the pair discussion was him/her (self). And the opportunity to express their opinions was very abundant compared to the PBL group discussion. Therefore, participants naturally got the opportunity to 'recognize themselves as important discussion members (2)' and 'actively concentrate on each other for discussion (2)'. Participants in pair discussion were perceived as a strong comrade who carried out the same tasks because the pair discussion was 'perceived as a discussion for the same goal (4)'.

In the paired discussion, the participants were able to 'explore data and/or knowledge predominantly and lead the discussion (1)' from the beginning to the end, unlike the PBL discussion that they had experienced in the past. Through this process, the participant experienced 'mature discussion technique (6)' and 'confidence of participating in debate (1)'.

In addition, the influence of the pair discussion on the participants' communication ability included 'learning the professional value of discussion and collaboration (1)'. Interestingly one of the participants experienced 'discordant in the topic of discussion (1)' because both she and her learning partner became interested in the further topics different from the one required to be discussed as time went through.

\section{Discussion}

This study aimed to analyze the influences of the pair discussion on the PBL class in nursing and regular classes. 
The results of this study showed that the pair discussion influenced the learning ability, problem solving ability, and communication ability of students participating in the PBL class. Those results are similar to previous studies in Korea that reported positive effects on interpersonal relations, creativity of individuals and groups, critical thinking, problem solving ability, communication ability and persuasion ability [10][11][12]. In addition, the results of this study showed that pair discussion can play a role in facilitating learning activities for students who have difficulties in debating and problem solving in PBL.

The result of this study is meaningful in that it provided basic data of instructional design and teaching and learning method to reduce burden on nursing students' PBL class and facilitate problem solving process. Based on the results of this study, we propose the simultaneous application of detailed learning ability training opportunities such as pair discussion to the application of 'teaching and learning' to enhance clinical thinking ability and problem solving ability of nursing students.

\section{References}

[1] H.S. Kim, The Journal of Korean Academic Society of Nursing Education, vol.3, pp.26-33, (1997)

[2] H. Ahn and K. Kang, Journal of the Korea Entertainment Industry Association, vol.11, no.7, pp.315-322, (2017)

[3] H. Choi, "The effects of PBL (Problem-Based Learning) on the metacognition, critical thinking, and problem solving process of nursing students," Journal of Korean Academy of Nursing, vol.34, no.5, pp.712-721, (2004)

[4] F. Greenwood, "Critique of the graduate nurse: An international perspective," Nurse Education Today, vol.20, no.1, pp.17-23, (2000) DOI: 10.1054/nedt.2000.0424

[5] H. Kim, I. Ko, W. Lee, S. Bae, and J. Shim, "Evaluation of problem-based learning in an undergraduate nursing course," Journal of Korean Academy of Child Health Nursing, vol.10, no.4, pp. 395-405, (2004)

[6] M.R. Yoo, Y.J. Choi, and M.S. Kang, "The effects of PBL (Problem-Based Learning) on the self-directed learning, critical thinking disposition, and problem solving process of nursing students," Journal of Korean Academy of Fundamentals of Nursing, vol.16, no.1, pp.46-55, (2009)

[7] H. Ju, I. Choi, B.D. Rhee, and J.T. Lee, "Challenges experienced by Korean medical students and tutors during problem-based learning: A cultural perspective," The Interdisciplinary Journal of Problem-Based Learning, vol.10, no.1, article no.8, (2016)

[8] H. Ju, "Effect of argumentation instruction on medical student experiences with problem-based learning," Korean Medical Education Review, vol.19, no.2, pp.101-108, (2017)

[9] O. Kent, “A theory of Havruta learning” Journal of Jewish Education, vol.76, no.3, pp.215-245, (2010)

[10] S. Kim, Theology and Ministry, vol.44, pp.389-415, (2015)

[11] Y.J. Hur, "The effect of Havruta teaching methods on university students' individual and group creativity," Korean Journal of General Education, vol.10, no.3, pp.73-106, (2016)

[12] S. Joung and H.J. Choi, The Korean Journal of Educational Methodology Studies, vol.27, no.1, pp.39-65, (2015)

[13] H. Son, "Understanding and application of qualitative content analysis," Journal of Korean Association for Qualitative Research, vol.2, pp.56-63, (2017) 
The Influences of Pair Discussion on Nursing Students' Learning Experience in Problem-Based Learning: A Qualitative Inquiry

This page is empty by intention. 